\title{
Association of physical activity with lung function in lung-healthy German adults: results from the KORA FF4 study
}

\author{
Agnes Luzak', Stefan Karrasch ${ }^{1,2,4}$, Barbara Thorand ${ }^{3}$, Dennis Nowak ${ }^{2,4}$, Rolf Holle ${ }^{5}$, Annette Peters ${ }^{3}$ \\ and Holger Schulz ${ }^{1,4^{*}}$
}

\begin{abstract}
Background: In lung disease, physical activity (PA) yields beneficial health effects, but its association with the function of healthy lungs has rarely been studied. We investigated the association of accelerometer-based PA with spirometric indices, maximal inspiratory mouth pressure $\left(\mathrm{PI}_{\max }\right)$ and lung diffusion capacity in lung-healthy adults.

Methods: In total, 341 apparently lung-healthy participants from the population-based KORA (Cooperative Health Research in the Region of Augsburg) FF4 cohort study (45\% male, aged 48-68 years, 47\% never smokers) completed lung function testing and wore ActiGraph accelerometers over a one week period at the hip. In adjusted regression analyses, moderate to vigorous PA (MVPA) was characterized as: sex-specific activity quartiles, achieving $\geq 10$ consecutive minutes (yes vs. no), and meeting the WHO PA recommendations (yes vs. no).

Results: Positive associations of MVPA-quartiles with forced expiratory volume in $1 \mathrm{~s}\left(\mathrm{FEV}_{1}\right)$, forced vital capacity (FVC), and corresponding Global Lung Function Initiative z-scores were found. Subjects in the most active quartile (> 47 or > $50 \mathrm{~min} /$ day for females and males, respectively) had $142 \mathrm{ml}$ [95\% Cl: 23, 260] higher FEV ${ }_{1}$ and $155 \mathrm{ml}$ [95\% Cl: 10, 301] higher FVC than those in the least active quartile $(<17$ or $<21 \mathrm{~min} /$ day for females and males, respectively); however these associations were stronger among ex-/current smokers. Achieving at least once 10 consecutive minutes of MVPA was only associated with higher $\mathrm{PI}_{\max }$ [ $\beta$-estimate: $0.57 \mathrm{kPa} ; 95 \% \mathrm{Cl}: 0.04,1.10$ ], remaining significant among never smokers. No associations were found with diffusion capacity or for reaching the WHO-recommended 150 min of MVPA/week in 10-min bouts.

Conclusions: Although the effects were small, active subjects showed higher spirometric results. The observed associations were more pronounced among ever smokers suggesting a higher benefit of PA for subjects being at a higher risk for chronic lung diseases.
\end{abstract}

Keywords: Lung function, Spirometry, Activity behavior, Accelerometer

\section{Background}

Physical activity (PA) reduces the risk of premature mortality and chronic diseases like cardiovascular disease or diabetes mellitus [1]. Benefits of activity apply also to persons with chronic lung diseases such as asthma or

\footnotetext{
* Correspondence: schulz@helmholtz-muenchen.de

${ }^{1}$ Institute of Epidemiology I, Helmholtz Zentrum München - German Research Center for Environmental Health, Ingolstädter Landstr. 1, 85764 Neuherberg, Germany

${ }^{4}$ Comprehensive Pneumology Center Munich (CPC-M), Member of the German Center for Lung Research, Max-Lebsche-Platz 31, 81377 Munich, Germany

Full list of author information is available at the end of the article
}

chronic obstructive pulmonary disease (COPD), who are therefore encouraged to engage in regular PA $[2,3]$. Studies have shown that higher PA was associated with a lower risk of hospital admissions and all-cause mortality in COPD patients [3, 4]. Furthermore, the diffusion capacity of the lung for carbon monoxide was shown to be a predictor of a decline in 6-min-walking distance in COPD patients [5]. Moreover, exercise training in COPD patients was associated with improved ventilatory muscle function and showed positive effects on the forced vital capacity (FVC) [6,7]. Due to the positive health effects of PA in patients with chronic lung 
diseases, PA has been incorporated into pulmonary rehabilitation programs [8].

In population-based studies, PA was shown to be associated with slower age-related decline of the forced expiratory volume in $1 \mathrm{~s}\left(\mathrm{FEV}_{1}\right)$ in adults $[9,10]$. Results from a longitudinal study among middle-aged men showed that those with higher levels of PA experienced slower lung function decline over 25 years [11]. However, all these studies assessed PA by questionnaires, which was found to correlate only low-to-moderately with activity objectively assessed by motion sensors in adults $[12,13]$.

Only a few studies have investigated the association of accelerometer-based PA with lung function. Moreover, the association between PA and lung function in lunghealthy persons is unclear. In lung-healthy adolescents, no associations were found between accelerometerbased PA and a broad range of spirometric parameters [14]. In adults, results of a study among 62 smokers showed that lung function between inactive participants, defined as those who engaged in less than $150 \mathrm{~min} /$ week of moderate to vigorous PA (MVPA), and active ones did not differ [15]. Thus, the evidence is inconclusive.

Furthermore, studies among athletes suggest that endurance exercise is associated with higher FVC and improved lung diffusion capacity [16, 17]. A study among 25 healthy men showed an improvement of maximal inspiratory pressure after 5 weeks of inspiratory muscle training [18], as observed in COPD patients after exercise training [6], whereas the increase in respiratory muscle endurance of marathon runners was described as a consequence of differences in breathing pattern developed during running rather than respiratory muscle strength [19].

Considering the limited evidence on the association between PA and lung function in lung-healthy populations, our aim was to investigate the association of accelerometer-based PA with lung function in apparently lung-healthy German adults from a population-based sample. Therefore, we addressed different aspects of lung function i.e. lung volume, airflow limitation, pulmonary gas exchange (TLCO/VA) and inspiratory muscle strength $\left(\mathrm{PI}_{\max }\right)$.

\section{Methods}

\section{Study population}

The present analysis was based on a follow-up study of the KORA S4 (KORA: Cooperative Health Research in the Region of Augsburg) cohort comprising 4261 adults (51.0\% female) examined in 1999 - 2001. A description of the primary study design has been published previously [20].

The selection of the study population is displayed in detail in Fig. 1. In the KORA FF4 follow-up study 2279 participants (51.6\% female) aged 38-88 years were examined between June 2013 and September 2014. Covering only the age range 48-68 years, 1043 of these participants were selected for the "Lung health \& physical activity" study, which comprised spirometry, assessment of

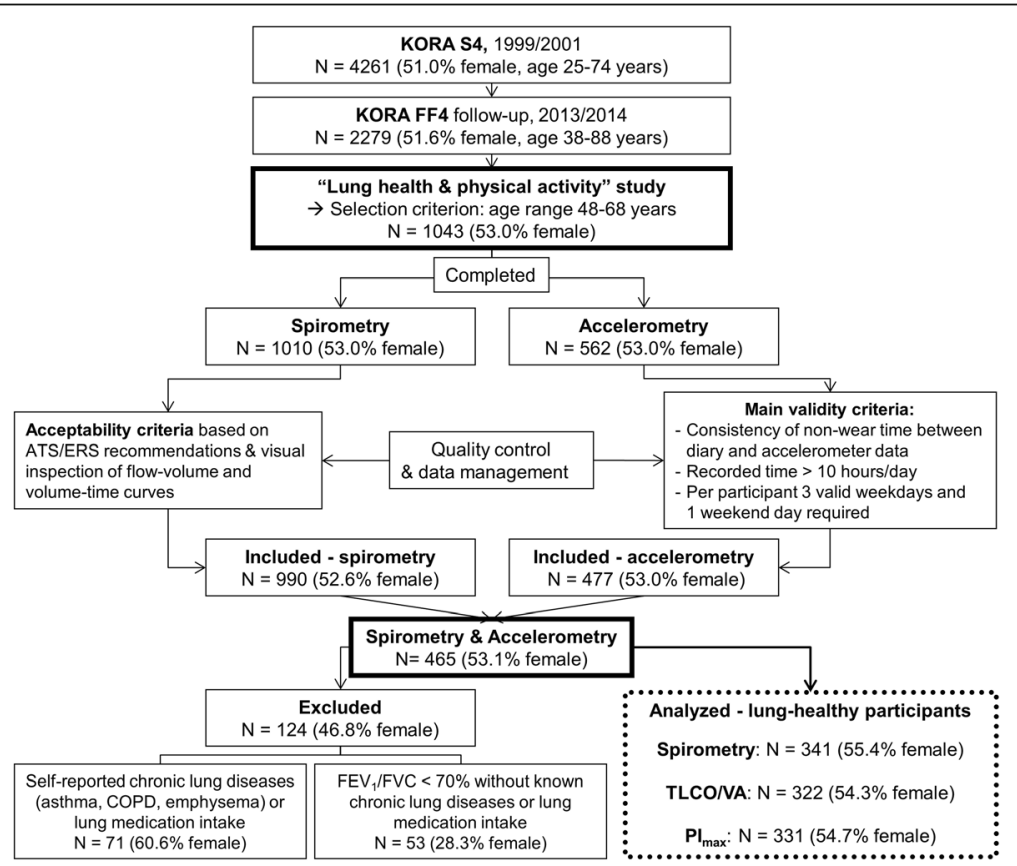

Fig. 1 Selection of participants. KORA: Cooperative Health Research in the Region of Augsburg. ATS: American Thoracic Society. ERS: European Respiratory Society. COPD: chronic obstructive pulmonary disease. FEV $\mathrm{F}_{1}$ forced expiratory volume in $1 \mathrm{~s}$. FVC: forced vital capacity. TLCONA: transfer factor of the lung for carbon monoxide adjusted for hemoglobin and divided by alveolar volume. $\mathrm{PI}_{\text {max }}$ : maximum inspiratory mouth pressure 
inspiratory muscle strength $\left(\mathrm{PI}_{\max }\right)$, measures of pulmonary gas exchange, and accelerometer-based assessment of habitual PA over one week. Information on sociodemographic variables, and current medication intake seven days before examination was obtained from standardized interviews and questionnaires. For the assessment of common diseases such as stroke or myocardial infarction, subjects were asked for each disease separately if a doctor has ever diagnosed this particular disease. Further, information on mobility and pain/discomfort was obtained from the EuroQol five dimensions questionnaire (EQ-5D 5 L) [21].

Of 1010 subjects who participated in spirometry, spirometric data of 990 participants were considered as valid based on international recommendations [22]. In accelerometry, two males with values greater than the mean plus seven times the standard deviation for weight and MVPA, respectively, were excluded during data management after quality control, resulting in 477 subjects with valid accelerometric data out of 562 who initially participated. For the selection of lung-healthy subjects, 465 subjects who had both, valid spirometry and accelerometry were considered. Subjects who reported a doctor's diagnosis of asthma, emphysema, chronic bronchitis or COPD, or used pulmonary medication including antileukotrienes, inhaled sympathomimetics, anticholinergics, and/or steroids were excluded from this analysis $(N=71)$. Furthermore, subjects with $\mathrm{FEV}_{1} / \mathrm{FVC}<0.7$ (indication of airflow limitation) were excluded $(N=53)$ [23]. Finally, 341 apparently lunghealthy subjects were available for the present analysis. Among these, $\mathrm{PI}_{\max }$ results were available for 331 subjects ( $54.7 \%$ female) and results for the transfer factor of the lung for carbon monoxide divided by alveolar volume (TLCO/VA) for 322 subjects (54.3\% female).

\section{Physical activity assessment}

A detailed description of the procedure, data handling, quality control and inclusion criteria has been reported previously [24]. In brief, participants were asked to wear an ActiGraph GT3X accelerometer (Pensacola, Florida) over a one week period at the hip from getting up until going to bed time and to complete a daily diary which included the time of getting up, going to sleep, and reasons for and duration of non-wear time. Non-wear time according to the accelerometer data was assessed based on the algorithm derived from the National Health and Nutrition Examination Survey [25]. Days were considered as not valid, if the difference between the non-wear time algorithm applied to the accelerometer data and the diary non-wear time was greater than $60 \mathrm{~min}$ (if the non-wear time was reported in the diary) or greater than $120 \mathrm{~min}$ (if the accelerometer indicated a non-wear time). Subjects were excluded in case of no reported non-wear time over the whole 7 day reporting period although the accelerometer should have been removed during water activities e.g. showering. Further exclusion criteria for single days were missing information on time spent awake, day length $<10 \mathrm{~h} /$ day, non-wear time during sport activities lasting $>2 \mathrm{~h}$, or incorrect handling of the accelerometer e.g. hand instead of hip. Further details of all exclusion criteria have been previously published [24]. Subjects were only included in the analysis if they had at least 3 valid weekdays and 1 valid weekend day. $89 \%$ of the subjects included in our analysis recorded at least 6 days, $9 \%$ had 5 days and $2 \%$ provided 4 days only. Measured accelerations of the vertical axis were stored at $1 \mathrm{~Hz}$ and converted into 1-min epochs classifying a moderate to vigorous PA (MVPA) level as $\geq 1952$ counts per minute, as proposed by Freedson et al. [26]. Non-wear time during sport was imputed as described here [14, 24].

Since the relationship between MVPA and lung function measures adjusted for sex, age, and height was non-linear, MVPA was divided into sex-specific quartiles. In addition, two further binary PA variables were built based on the World Health Organization (WHO) recommendation stating that adults should accumulate at least $150 \mathrm{~min}$ of MVPA/week in bouts of at least $10 \mathrm{~min}$ [27].

PA was quantified as exposure in three ways: (1) sexspecific MVPA quartiles; (2) achieving at least one 10-min bout of MVPA over the whole measurement period (yes vs. no); (3) reaching the WHO threshold of $150 \mathrm{~min}$ MVPA/week in at least 10-min bouts (yes vs. no). Cut-offs for sex-specific MVPA quartiles were set as follows: cutoff for males: $1 \mathrm{st} \leq 21.6 \mathrm{~min} /$ day, $2 \mathrm{nd}>21.6-35.2 \mathrm{~min} /$ day, 3rd > 35.2-49.9 $\mathrm{min} /$ day, 4 th $>49.9 \mathrm{~min} /$ day; and cut-offs for females: 1 st $\leq 17.2 \mathrm{~min} /$ day, $2 \mathrm{nd}>17.2-28.3 \mathrm{~min} /$ day, 3 rd $>28.3-46.7 \mathrm{~min} /$ day, 4 th $>46.7 \mathrm{~min} /$ day, respectively.

\section{Lung function assessment}

Lung function assessment was performed in line with the American Thoracic Society (ATS) and European Respiratory Society (ERS) statements [22, 28, 29].

Flow-volume curves were obtained using a pneumotachograph-type spirometer (MasterScope, Jaeger, Hoechberg, Germany). Subjects were guided to perform at least 3 and up to 8 spirometric maneuvers per test in order to obtain acceptable and reproducible values. During the maneuvers both flow-volume and volume-time curves were monitored online by a trained examiner. After each test, the curves were visually inspected, artifacts e.g. coughing were excluded and the results were selected and evaluated according to the ATS/ERS recommendations [22], including a good start with extrapolated volume $<0.5 \%$ of FVC or $0.15 \mathrm{l}$, an exhalation of $\geq 6 \mathrm{~s}$ or a plateau in volumetime curve. Spirometric parameters included $\mathrm{FEV}_{1}$, FVC, $\mathrm{FEV}_{1} / \mathrm{FVC}$, and forced expiratory flow between $25 \%$ and 
$75 \%$ of exhaled FVC ( $\left.\mathrm{FEF}_{25-75}\right)$. Standardized z-scores were calculated using reference equations for spirometry from the Global Lung Function Initiative (GLI) [30]. TLCO was determined using the single-breath technique. Subjects were asked to perform a maximum of 5 trials in order to achieve acceptable and reproducible values with an inspired volume $>85 \%$ of the largest vital capacity in $<4 \mathrm{~s}$, and an effective breath hold time within 8 to $12 \mathrm{~s}$ according to ATS/ERS recommendations [28]. TLCO results were adjusted for hemoglobin obtained from blood samples collected on the day of the physical examination in the study center [28]. For determination of PI $\mathrm{max}_{\max }$, subjects were instructed to exhale to residual volume followed by a maximal voluntary inspiration against an obstructed mouth piece with a small leak to prevent glottic closure using a flanged mouth piece [29]. The highest peak inspiratory pressure achieved during a minimum of 3 and a maximum of 15 maneuvers was used for analysis (MasterScreen PFT, Jaeger, Hoechberg, Germany).

\section{Statistical analyses}

Sex-specific differences were assessed using Pearson's Chi-squared test (categorical variables), the t-test (normal distribution), and Wilcoxon rank-sum test (skewed distribution). Mean and corresponding standard deviation or percentages $(\%, N)$ were used to describe subject characteristics and categorized PA. Due to a non-normal distribution, median and 1st and 3rd quartiles were reported for continuous MVPA.

Adjusted linear regression models were applied to analyze associations between PA and lung function parameters. Since spirometric parameters $\left(\mathrm{FEV}_{1}, \mathrm{FVC}\right.$, and $\mathrm{FEF}_{25-75}$ ) were correlated ( $r=0.61$ to 0.98 ), the results of regression analyses were not adjusted for multiple testing. For each spirometric parameter, the mean plus/ minus 4 times the standard deviation was calculated for each sex to determine sex-specific outliers. According to this definition one subject was excluded in the analyses using z-scores for $\mathrm{FEV}_{1}$ and $\mathrm{FVC}$ and another in $\mathrm{FEF}_{25-}$ 75 models. The main model was adjusted for sex, age, height, weight, smoking status categorized as never, ex-, or current smokers, education level categorized as low ( $<10$ years of school, i. e. "Hauptschule" in Germany), middle (10 years of school, i.e. "Realschule") and high (>10 years of school, i.e. "Gymnasium"), and a doctor's diagnosis of hay fever (ever). Regression models for standardized GLI z-scores [30] that are already adjusted for ethnicity, sex, age, and height, were adjusted only for additional variables. Covariates remained in the model independent of statistical significance. As the mean body mass index (BMI) was $27.7 \mathrm{~kg} / \mathrm{m}^{2}$ we included a sensitivity analysis, replacing weight with BMI in the main analysis.
To assess if the association might be modified through other covariates potentially associated with lung function, sensitivity analyses were done. Since smoking behavior has an impact on lung function and might modify potential associations, we calculated the main regression model with stratification into never and ex-/current smokers. In further analyses, the main model was additionally adjusted for moderate to extreme problems in walking about and/or pain or discomfort, season categorized as winter (start of measurement: December to February), spring (March to May), summer (June to August), and autumn (September to November), or for self-reported acute respiratory infections in the last three weeks prior to lung function testing. All participants were Caucasian therefore ethnicity was not included as a covariate. Interaction effects between MVPA and sex were tested in the main model. In case of significant interaction effects $(p<0.05)$, stratified results were reported additionally.

To eliminate a possible impact of myocardial infarction and/or stroke $(N=15)$, subjects with a history of these events were excluded from the main model as a further sensitivity analysis.

The statistical program $R$, version 3.3.3 [31], was used for all analyses and $p$-values below 0.05 were considered statistically significant.

\section{Results}

The study population consisted of 341 (45\% male) apparently lung-healthy subjects (i.e. no chronic lung diseases or pulmonary medication intake, and $\mathrm{FEV}_{1} / \mathrm{FVC} \geq 0.7$ ) with a mean age of 57 years (Table 1). The prevalence of current smoking was $14 \%$, while $47 \%$ of the participants reported to be never smokers. Despite a lower prevalence of females among all ex-/current smokers than among never smokers $(50.0 \%$ and $61.6 \%$, respectively), $70.2 \%$ of current smokers were female. BMI was comparable between never and ex-/current smokers. Mean z-scores were lower among ex-/current smokers compared to never smokers, being statistically significant for z-score $\mathrm{FEF}_{25-75}$. Nevertheless, smoking status did not affect PA (Additional file 1: Table S1). Included subjects were slightly younger (mean age of 57 years vs. 58 years, respectively) and more often never smokers $(46.6 \%$ vs. $37.8 \%$, respectively) compared to all other subjects performing spirometry (Additional file 1: Table S2).

Overall, participants spent a median of $31 \mathrm{~min} /$ day in MVPA with a range from 1 to 111 mean $\mathrm{min} /$ day, being lower for females than for males (median 28 vs. 35 min, respectively). In total, $66 \%$ of subjects achieved at least one 10-min bout of MVPA, and 15\% achieved the recommended $150 \mathrm{~min}$ of MVPA/week in at least 10-min bouts (Table 1). 
Table 1 Population characteristics, lung function and physical activity measurements

\begin{tabular}{|c|c|c|}
\hline & Males $(n=152)$ & Females $(n=189)$ \\
\hline \multicolumn{3}{|l|}{ Age } \\
\hline mean years (SD) & $57.1(5.8)$ & $57.5(5.3)$ \\
\hline \multicolumn{3}{|l|}{ Height * } \\
\hline mean cm (SD) & $177.0(6.0)$ & $162.1(6.0)$ \\
\hline \multicolumn{3}{|l|}{ Weight * } \\
\hline mean kg (SD) & $88.8(13.5)$ & $71.5(14.4)$ \\
\hline \multicolumn{3}{|l|}{$B M l^{*}$} \\
\hline n normal (BMI < 25) (\%) & $27(17.8)$ & $79(41.8)$ \\
\hline n overweight ( $\geq 25 \mathrm{BMl}<30$ ) (\%) & $83(54.6)$ & $61(32.3)$ \\
\hline n obese $(\mathrm{BMI} \geq 30)(\%)$ & $42(27.6)$ & $49(25.9)$ \\
\hline \multicolumn{3}{|l|}{ Smoking status* } \\
\hline n never smokers (\%) & $61(40.1)$ & $98(51.9)$ \\
\hline n ex-smokers (\%) & $77(50.7)$ & $58(30.7)$ \\
\hline n current smokers (\%) & $14(9.2)$ & $33(17.5)$ \\
\hline \multicolumn{3}{|l|}{ Education* } \\
\hline $\mathrm{n}$ low $(<10$ years of school) (\%) & $68(44.7)$ & $84(44.4)$ \\
\hline $\mathrm{n}$ medium (10 years of school) (\%) & $34(22.4)$ & $66(34.9)$ \\
\hline $\mathrm{n}$ high (> 10 years of school) (\%) & $50(32.9)$ & $39(20.6)$ \\
\hline \multicolumn{3}{|l|}{ Hay fever } \\
\hline $\mathrm{n}$ yes $(\%)$ & $22(14.5)$ & $43(22.8)$ \\
\hline \multicolumn{3}{|c|}{ Problems in walking about, and/or pain or discomfort } \\
\hline n not at all/slight (\%) & $135(88.8)$ & $154(81.9)$ \\
\hline n moderate/extreme (\%) & $17(11.2)$ & $34(18.1)$ \\
\hline \multicolumn{3}{|l|}{ Lung function } \\
\hline \multicolumn{3}{|l|}{$\mathrm{FEV}_{1}^{*}$} \\
\hline mean I (SD) & $3.76(0.57)$ & $2.66(0.42)$ \\
\hline \multicolumn{3}{|l|}{$\mathrm{FVC}^{*}$} \\
\hline mean I (SD) & $4.88(0.71)$ & $3.39(0.56)$ \\
\hline \multicolumn{3}{|l|}{$\mathrm{FEV}_{1} / \mathrm{FVC}^{*}$} \\
\hline mean \% (SD) & $77.08(3.93)$ & $78.5(4.14)$ \\
\hline \multicolumn{3}{|l|}{$\mathrm{FEF}_{25-75^{*}}$} \\
\hline mean I/s (SD) & $3.16(0.91)$ & $2.37(0.63)$ \\
\hline \multicolumn{3}{|l|}{ Z-score FEV ${ }_{1}$} \\
\hline mean (SD) & $0.25(0.86)$ & $0.32(0.91)$ \\
\hline \multicolumn{3}{|l|}{ Z-score FVC } \\
\hline mean (SD) & $0.29(0.80)$ & $0.35(0.87)$ \\
\hline \multicolumn{3}{|l|}{ Z-score FEV $1 / F V C$} \\
\hline mean (SD) & $-0.12(0.58)$ & $-0.15(0.63)$ \\
\hline \multicolumn{3}{|l|}{ Z-score $\mathrm{FEF}_{25-75}$} \\
\hline mean (SD) & $-0.01(0.78)$ & $-0.01(0.80)$ \\
\hline \multicolumn{3}{|l|}{ TLCO, hemoglobin adjusted* } \\
\hline mean $\mathrm{mmol} / \mathrm{min} / \mathrm{kPa}(\mathrm{SD})$ & $9.88(1.50)$ & $6.90(1.07)$ \\
\hline \multicolumn{3}{|l|}{ TLCONA* } \\
\hline mean mmol/min/kPa/l (SD) & $1.45(0.16)$ & $1.38(0.18)$ \\
\hline
\end{tabular}


Table 1 Population characteristics, lung function and physical activity measurements (Continued)

\begin{tabular}{|c|c|c|}
\hline & Males $(n=152)$ & Females $(n=189)$ \\
\hline \multicolumn{3}{|l|}{$\mathrm{PI}_{\max }{ }^{*}$} \\
\hline mean kPa (SD) & $9.77(2.53)$ & $6.67(2.12)$ \\
\hline \multicolumn{3}{|l|}{ Physical activity } \\
\hline \multicolumn{3}{|l|}{ MVPA* $^{*}$} \\
\hline median of mean min/day (1st; 3rd quartile) & $35.2(21.6 ; 49.9)$ & $28.3(17.2 ; 46.7)$ \\
\hline \multicolumn{3}{|l|}{ 10-min bout of MVPA achieved } \\
\hline n yes $(\%)$ & $104(68.4)$ & $120(63.5)$ \\
\hline \multicolumn{3}{|l|}{ WHO threshold achieved } \\
\hline $\mathrm{n}$ yes $(\%)$ & $24(15.8)$ & $26(13.8)$ \\
\hline
\end{tabular}

$S D$ standard deviation, $B M I$ body mass index, $F E V_{1}$ forced expiratory volume in $1 \mathrm{~s}$, $F V C$ forced vital capacity, $F E F_{25-75}$ forced expiratory flow between $25 \%$ and $75 \%$ of FVC, TLCO/VA transfer factor of the lung for carbon monoxide adjusted for hemoglobin and divided by alveolar volume, $P I_{\text {max }}$ maximum inspiratory mouth pressure, MVPA moderate to vigorous physical activity

${ }^{*} p<0.05$ (males vs. females)

\section{Physical activity and spirometric parameters}

In the total population, being in the most active MVPA quartile was associated with higher $\mathrm{FEV}_{1}, \mathrm{FVC}, \mathrm{FEV}_{1} \mathrm{z}-$ score and FVC z-score (Table 2, Additional file 1: Table S3). $\mathrm{FEV}_{1}$ was $142 \mathrm{ml}$ higher in the most active subjects, i.e. females that engaged $>47 \mathrm{~min} /$ day and males that engaged $>50 \mathrm{~min} /$ day in MVPA, than in the least active quartile, i.e. $<17 \mathrm{~min} /$ day for females or $<21 \mathrm{~min} /$ day for males. Stratified analyses revealed that these associations remained in ex-/current smokers, but not in never smokers (Table 2).

The results for FVC were comparable to those observed for $\mathrm{FEV}_{1}$, except for an interaction effect between the third MVPA quartile and sex that was present for FVC only. After stratification an association was found for females only (Additional file 1: Table S4). Sensitivity analyses, e.g. further adjustment for walking difficulties and/ or discomfort, and exclusion of subjects with stroke and/ or myocardial infarction did not substantially change our results. Adjusting for BMI instead of weight led to the very similar results (Additional file 1: Table S5).

When MVPA was quantified as achieving at least one 10-min bout, an association with lung function was found in sex-stratified analyses for $\mathrm{FEV}_{1}, \mathrm{FVC}$, zscores for FEV 1 and FVC in females only (Additional file 1: Tables S4 and S6). Reaching the recommended $150 \mathrm{~min}$ of $\mathrm{MVPA} /$ week in at least 10min bouts was negatively associated with $\mathrm{FEV}_{1}, \mathrm{FVC}$,

Table 2 Association of physical activity with spirometric parameters

\begin{tabular}{|c|c|c|c|c|c|c|c|}
\hline & \multirow{2}{*}{$\begin{array}{l}\text { MVPA } \\
\text { Quartile }^{a}\end{array}$} & \multicolumn{2}{|l|}{$\begin{array}{l}\text { Total population } \\
(n=341)\end{array}$} & \multicolumn{2}{|l|}{$\begin{array}{l}\text { Never smokers } \\
(n=159)\end{array}$} & \multicolumn{2}{|c|}{$\begin{array}{l}\text { Ex- and current smokers } \\
(n=182)\end{array}$} \\
\hline & & $\beta(95 \% \mathrm{Cl})$ & $p$-value & $\beta(95 \% \mathrm{Cl})$ & $p$-value & $\beta(95 \% \mathrm{Cl})$ & $p$-value \\
\hline \multirow[t]{3}{*}{$\mathrm{FEV}_{1}, \mathrm{ml}$} & 2 & $72(-44,188)$ & 0.22 & $44(-129,218)$ & 0.62 & $81(-78,240)$ & 0.32 \\
\hline & 3 & $124(7,242)$ & 0.04 & $167(-7,341)$ & 0.06 & $60(-104,224)$ & 0.47 \\
\hline & 4 & $142(23,260)$ & 0.02 & $84(-89,257)$ & 0.34 & $195(29,360)$ & 0.02 \\
\hline \multirow[t]{3}{*}{$\mathrm{FVC}, \mathrm{ml}$} & 2 & $91(-52,235)$ & 0.21 & $48(-160,256)$ & 0.65 & $114(-87,316)$ & 0.27 \\
\hline & 3 & $107(-38,251)$ & 0.15 & $190(-18,398)$ & 0.08 & $11(-196,219)$ & 0.92 \\
\hline & 4 & $155(10,301)$ & 0.04 & $75(-132,282)$ & 0.48 & $227(18,437)$ & 0.04 \\
\hline \multirow[t]{3}{*}{$\mathrm{FEV}_{1} / \mathrm{FVC}, \%$} & 2 & $0.01(-1.18,1.21)$ & 0.98 & $-0.03(-1.86,1.80)$ & 0.97 & $-0.10(-1.72,1.51)$ & 0.90 \\
\hline & 3 & $0.87(-0.34,2.07)$ & 0.16 & $0.33(-1.50,2.17)$ & 0.72 & $1.07(-0.59,2.74)$ & 0.21 \\
\hline & 4 & $0.64(-0.57,1.85)$ & 0.30 & $0.70(-1.12,2.52)$ & 0.45 & $0.56(-1.12,2.24)$ & 0.51 \\
\hline \multirow[t]{3}{*}{$\mathrm{FEF}_{25-75}, \mathrm{ml} / \mathrm{s}$} & 2 & $100(-120,319)$ & 0.37 & $61(-266,388)$ & 0.71 & $101(-201,403)$ & 0.51 \\
\hline & 3 & $277(56,499)$ & 0.01 & $239(-89,566)$ & 0.16 & $246(-65,558)$ & 0.12 \\
\hline & 4 & $161(-63,384)$ & 0.16 & $106(-220,433)$ & 0.52 & $213(-102,527)$ & 0.19 \\
\hline
\end{tabular}

MVPA moderate to vigorous physical activity, $\mathrm{Cl}$ confidence interval, $F E V_{1}$ forced expiratory volume in $1 \mathrm{~s}, F V C$ forced vital capacity, $F E F_{25-75}$ forced expiratory flow between $25 \%$ and $75 \%$ of FVC

aLeast active MVPA quartile (1st quartile) was used as reference. All models were adjusted for sex, age, height, weight, education level, a doctor's diagnosis of hay fever and depending on the population analyzed also by smoking status (never, ex- or current)

Statistically significant associations $(p<0.05)$ are shown in bold 
and z-scores for $\mathrm{FEV}_{1}$ and FVC in males only (Additional file 1: Tables S4 and S7).

\section{Physical activity and inspiratory muscle strength}

Subjects who engaged in at least one 10-min bout of MVPA had an estimated increase of $\mathrm{PI}_{\max }$ by $0.6 \mathrm{kPA}$ (Table 3). However, in analyses stratified by smoking status, this association was significant only in never smokers (Additional file 1: Table S8).

\section{Physical activity and pulmonary gas exchange}

PA was not associated with TLCO/VA in any analysis, except for a negative association found with the third MVPA quartile among never smokers (Table 3, Additional file 1: Table S8).

\section{Discussion}

The present analyses revealed weak positive associations between the most active subjects and volumetric indices in adults without lung function limitation. These associations were primarily observed among ex-/current smokers, but not in never smokers, suggesting that the effect might be driven by smoking behaviour. While PA showed no association with TLCO/VA, $\mathrm{PI}_{\max }$ was higher in subjects who engaged in at least one 10-min bout of MVPA during the recording period, compared to those who did not.

Compared to current recommendations PA was rather low in our population-based cohort. Median daily MVPA was $31 \mathrm{~min}$, and only $15 \%$ of subjects met the WHO PA recommendation. This finding, however, is comparable to results obtained through the questionnaire-based German Health Interview and Examination Survey for Adults where $18 \%$ of 50 69 year old participants achieved the WHO activity threshold [32].
Still, weak associations with lung function were present in our analyses.

An association between $\mathrm{PI}_{\max }$ and the achievement of at least one 10-min bout of MVPA was found in our population, remaining significant in never smokers only. In COPD, twitch mouth pressure has previously been shown to decrease with increasing disease severity and $\mathrm{PI}_{\max }$ could be improved by exercise training $[6,33]$. A study among marathon athletes compared to sedentary controls reported a higher respiratory muscle endurance in the athletes - probably as a result of breath technique, but a similar $\mathrm{PI}_{\max }$ [19].

In our population, those who reached at least one 10min bout spent in MVPA showed a higher $\mathrm{PI}_{\max }$, while reaching the WHO PA recommendation showed no increase. It might be that the threshold of engaging for at least 10 consecutive minutes in habitual MVPA, i.e. separating subjects with short bouts of activity and those with at least sporadic activity for $10 \mathrm{~min}$, might represent a plateau. However, this result should be interpreted with caution due to the weak associations found and the potentially minor clinical relevance.

While TLCO has previously been shown to be a clinically relevant predictor of exercise capacity determined by 6-min-walking distance test in COPD patients [5], PA was not found to be a predictor of TLCO/VA in our apparently lung-healthy population. The lack of findings might be due to the possibly small effects that could not be detected in habitual PA of middle-aged adults without lung function limitation.

Our results show a weak, but positive association of PA and volumetric lung function indices, primarily seen among ex-/current smokers. Compared to the least active subjects, subjects engaging on average more than about $48 \mathrm{~min} /$ day in MVPA had a $142 \mathrm{ml}$ higher $\mathrm{FEV}_{1}$. Considering an annual decline of around $25 \mathrm{ml}$ of $\mathrm{FEV}_{1}$

Table 3 Association of physical activity with pulmonary gas exchange and inspiratory muscle strength

\begin{tabular}{|c|c|c|c|c|}
\hline & \multicolumn{2}{|c|}{ Pulmonary gas exchange (TLCO/NA), $10^{-1} \mathrm{mmol} / \mathrm{min} / \mathrm{kPa} / \mathrm{l}$} & \multicolumn{2}{|c|}{ Maximum inspiratory mouth pressure $\left(\mathrm{PI}_{\max }\right), \mathrm{kPa}$} \\
\hline & $\beta(95 \% \mathrm{Cl})$ & $p$-value & $\beta(95 \% \mathrm{Cl})$ & $p$-value \\
\hline \multicolumn{5}{|l|}{ MVPA quartiles, } \\
\hline 1st - least active (reference) & - & - & - & - \\
\hline 2nd & $0.01(-0.47,0.49)$ & 0.98 & $0.39(-0.32,1.10)$ & 0.28 \\
\hline $3 r d$ & $-0.30(-0.80,0.19)$ & 0.23 & $0.23(-0.48,0.94)$ & 0.53 \\
\hline 4th - most active & $0.25(-0.25,0.75)$ & 0.33 & $0.05(-0.68,0.78)$ & 0.90 \\
\hline \multicolumn{5}{|l|}{ 10-min bout of MVPA achieved, } \\
\hline yes vs. no & $-0.03(-0.39,0.34)$ & 0.88 & $0.57(0.04,1.10)$ & 0.04 \\
\hline \multicolumn{5}{|l|}{ WHO threshold achieved, } \\
\hline yes vs. no & $0.36(-0.13,0.84)$ & 0.15 & $0.00(-0.71,0.71)$ & 1.00 \\
\hline
\end{tabular}


in adults [34, 35], our results would correspond to an age-related decline of about 5 years. No causal relationships or long-term effects can be drawn from our crosssectional analysis, but our results are in line with those from a longitudinal study observing that current smokers with moderate and high PA had a decreased decline in $\mathrm{FEV}_{1}$ and $\mathrm{FVC}$ compared with smokers with low PA [36]; and as in our study, this association was not observed in never smokers. A study including only smokers did not find an association between the achievement of at least $150 \mathrm{~min} /$ week of MVPA and spirometric parameters [15]. However, observed differences may be related to diverse designs, population characteristics and definitions of being active [15, 36]. PA was suggested to promote an anti-inflammatory status and to potentially protect against chronic diseases associated with low-grade systemic inflammation [37]. Smokers are at a higher risk for COPD and other smoking-related diseases typically experiencing a low-grade systemic inflammation [38]. In our analysis, the positive associations between being active and volumetric indices were more pronounced among ex-/current smokers, suggesting a higher benefit of PA for subjects being at a higher risk for chronic lung diseases.

\section{Strength and limitations}

A major strength of this study is the investigation of a range of standardized lung function parameters obtained by spirometry, as well as less often investigated measures of gas exchange and respiratory muscle strength in apparently lung-healthy adults. We objectively assessed PA by accelerometry, which is rare, as most available studies assessed PA by questionnaires [9-11, 36]. Evidence for the association between PA and lung function in the general population without chronic lung diseases is likewise rare.

Due to the cross-sectional design of our analysis, it is not possible to draw conclusions about long-term effects or causal relations. Although associations were found, these results should be interpreted with caution due to the small effects seen with partly wide confidence intervals. Further, the present results are limited to the pre-selected lung-healthy study population, comprising 48-68 year old residents in the region of Augsburg in southern Germany. Information on chronic lung diseases was assessed via self-report and was not individually verified by a physician.

\section{Conclusions}

Objective measurements of physical activity showed a weak, but positive association with slightly higher volumetric lung function indices in lung-healthy adults from southern Germany. This association was mainly observed among ex-/current smokers. Further, engaging in MVPA for at least 10 consecutive minutes was associated with higher $\mathrm{PI}_{\max }$, remaining significant in never smokers only. No associations were found for TLCO/ VA. Although the effects were small, our results suggest a positive association of PA with lung function of lunghealthy subjects from a population-based cohort.

\section{Additional file}

Additional file 1: Results of Tables S1 to S8. (PDF $521 \mathrm{~kb}$ )

\section{Abbreviations}

BMI: Body mass index; $\mathrm{Cl}$ : Confidence interval; $\mathrm{FEF}_{25-75}$ : Forced expiratory flow between $25 \%$ and $75 \%$ of FVC; FEV : Forced expiratory volume in $1 \mathrm{~s}$; FVC: Forced vital capacity; GLI: Global Lung Function Initiative; MVPA: Moderate to vigorous physical activity; PA: Physical activity; $\mathrm{PI}_{\text {max }}$ : Maximum inspiratory mouth pressure; SD: Standard deviation; TLCO/ VA: Transfer factor of the lung for carbon monoxide adjusted for hemoglobin and divided by alveolar volume; WHO: World Health Organization

\section{Acknowledgements}

The authors express appreciation to all attendees for their active participation in the KORA study. The authors thank the field staff in Augsburg conducting the KORA studies.

\section{Funding}

The KORA study was initiated and financed by the Helmholtz Zentrum München - German Research Center for Environmental Health, which is funded by the German Federal Ministry of Education and Research (BMBF) and by the State of Bavaria. This work was further supported by the Comprehensive Pneumology Center Munich (CPC-M) as member of the German Center for Lung Research and by the Competence Network Asthma and COPD (ASCONET), network COSYCONET (subproject 2, BMBF FKZ 01GI0882) funded by the German Federal Ministry of Education and Research (BMBF).

\section{Availability of data and materials}

The authors confirm that, for approved reasons, access restrictions apply to the data underlying the findings. The informed consent given by KORA study participants does not cover data posting in public databases. Applications for access to the data sets can be found at the following link: https://www.helmholtz-muenchen.de/en/kora/for-scientists/cooperationwith-kora/index.html. Data are available upon request from KORA-gen (http://epi.helmholtz-muenchen.de/kora-gen/) by means of a project agreement. Requests should be sent to kora.passt@helmholtz-muenchen.de and are subject to approval by the KORA Board.

\section{Authors' contributions}

$A L, D N$ and HS were involved in the conception and design of the study. SK, $\mathrm{BT}, \mathrm{RH}, \mathrm{AP}$ and $\mathrm{HS}$ contributed with data acquisition and data coding and AL with statistical analyses. AL, DN and HS contributed to the interpretation of the findings. AL drafted the manuscript and all authors revised it critically for important intellectual content and approved the final version.

\section{Ethics approval and consent to participate}

The study was approved by the responsible ethics committee of the Bavarian Medical Association. The investigations were carried out in accordance with the Declaration of Helsinki. All participants provided written informed consent.

\section{Consent for publication}

Not applicable.

Competing interests

The authors declare that they have no competing interests. 


\section{Publisher's Note}

Springer Nature remains neutral with regard to jurisdictional claims in published maps and institutional affiliations.

\section{Author details \\ 'Institute of Epidemiology I, Helmholtz Zentrum München - German Research Center for Environmental Health, Ingolstädter Landstr. 1, 85764 Neuherberg, Germany. ${ }^{2}$ Institute and Outpatient Clinic for Occupational, Social and Environmental Medicine, University Hospital of Munich (LMU), Ziemssenstr. 1, 80336 Munich, Germany. ${ }^{3}$ Institute of Epidemiology II, Helmholtz Zentrum München - German Research Center for Environmental Health, Ingolstädter Landstr. 1, 85764 Neuherberg, Germany. ${ }^{4}$ Comprehensive Pneumology Center Munich (CPC-M), Member of the German Center for Lung Research, Max-Lebsche-Platz 31, 81377 Munich, Germany. ${ }^{5}$ Institute of Health Economics and Health Care Management, Helmholtz Zentrum München - German Research Center for Environmental Health, Ingolstädter Landstr. 1, 85764 Neuherberg, Germany.}

Received: 13 March 2017 Accepted: 15 December 2017

Published online: 28 December 2017

\section{References}

1. Warburton DER, Charlesworth S, Ivey A, Nettlefold L, Bredin SSD. A systematic review of the evidence for Canada's physical activity guidelines for adults. Int J Behav Nutr Phys Act. 2010;7:39

2. Carson KV, Chandratilleke MG, Picot J, Brinn MP, Esterman AJ, Smith BJ. Physical training for asthma. Cochrane Database Syst Rev. 2013(9):Cd001116. DOl:10.1002/14651858.CD001116.pub4.

3. Garcia-Aymerich J, Lange P, Benet M, Schnohr P, Anto JM. Regular physical activity reduces hospital admission and mortality in chronic obstructive pulmonary disease: a population based cohort study. Thorax. 2006;61(9):772-8.

4. Waschki B, Kirsten A, Holz O, Muller KC, Meyer T, Watz H, et al. Physical activity is the strongest predictor of all-cause mortality in patients with COPD: a prospective cohort study. Chest. 2011;140(2):331-42.

5. Diaz AA, Pinto-Plata V, Hernandez C, Pena J, Ramos C, Diaz JC, et al. Emphysema and DLCO predict a clinically important difference for 6MWD decline in COPD. Respir Med. 2015;109(7):882-9.

6. Cortopassi F, Castro AA, Porto EF, Colucci M, Fonseca G, Torre-Bouscoulet L, et al. Comprehensive exercise training improves ventilatory muscle function and reduces dyspnea perception in patients with COPD. Monaldi Arch Chest Dis. 2009;71(3):106-12.

7. Strasser B, Siebert U, Schobersberger W. Effects of resistance training on respiratory function in patients with chronic obstructive pulmonary disease: a systematic review and meta-analysis. Sleep Breath. 2013;17(1):217-26.

8. Ries AL, Bauldoff GS, Carlin BW, Casaburi R, Emery CF, Mahler DA, et al. Pulmonary rehabilitation: joint ACCP/AACVPR evidence-based clinical practice guidelines. Chest. 2007;131(5 Suppl):4S-42S.

9. Nystad W, Samuelsen SO, Nafstad P, Langhammer A. Association between level of physical activity and lung function among Norwegian men and women: the HUNT study. Int J Tuberc Lung Dis. 2006;10(12):1399-405.

10. Jakes RW, Day NE, Patel B, Khaw K-T, Oakes S, Luben R, et al. Physical inactivity is associated with lower forced expiratory volume in 1 second: European prospective investigation into cancer-Norfolk prospective population study. Am J Epidemiol. 2002;156(2):139-47.

11. Pelkonen $M$, Notkola I-L, Lakka T, Tukiainen HO, Kivinen P, Nissinen A. Delaying decline in pulmonary function with physical activity. Am J Respir Crit Care Med. 2003;168(4):494-9.

12. Prince SA, Adamo KB, Hamel ME, Hardt J, Gorber SC, Tremblay M. A comparison of direct versus self-report measures for assessing physical activity in adults: a systematic review. Int J Behav Nutr Phys Act. 2008;5:56.

13. Skender S, Ose J, Chang-Claude J, Paskow M, Bruhmann B, Siegel EM, et al. Accelerometry and physical activity questionnaires - a systematic review. BMC Public Health. 2016;16:515

14. Smith MP, von Berg A, Berdel D, Bauer CP, Hoffmann B, Koletzko S, et al. Physical activity is not associated with spirometric indices in lung-healthy German youth. Eur Respir J. 2016;48(2):428-40.

15. Barboza ML, Barbosa AC, Spina GD, Sperandio EF, Arantes RL, Gagliardi AR, et al. Association between physical activity in daily life and pulmonary function in adult smokers. J Bras Pneumol. 2016;42(2):130-5.
16. Lazovic B, Mazic S, Suzic-Lazic J, Djelic M, Djordjevic-Saranovic S, Durmic T, et al. Respiratory adaptations in different types of sport. Eur Rev Med Pharmacol Sci. 2015;19(12):2269-74.

17. Degens $\mathrm{H}$, Rittweger J, Parviainen $\mathrm{T}$, Timonen $\mathrm{KL}$, Suominen $\mathrm{H}$, Heinonen $\mathrm{A}$, et al. Diffusion capacity of the lung in young and old endurance athletes. Int J Sports Med. 2013;34(12):1051-7.

18. Ramsook AH, Molgat-Seon Y, Schaeffer MR, Wilkie SS, Camp PG, Reid WD, et al. Effects of inspiratory muscle training on respiratory muscle electromyography and dyspnea during exercise in healthy men. J Appl Physiol (1985). 2017;122(5):1267-75.

19. Eastwood PR, Hillman DR, Finucane KE. Inspiratory muscle performance in endurance athletes and sedentary subjects. Respirology. 2001;6(2):95-104.

20. Holle R, Happich M, Lowel H, Wichmann HE. KORA-a research platform for population based health research. Gesundheitsw. 2005;67(Suppl 1):S19-25.

21. Rabin R, de Charro F. EQ-5D: a measure of health status from the EuroQol group. Ann Med. 2001;33(5):337-43.

22. Miller MR, Hankinson J, Brusasco V, Burgos F, Casaburi R, Coates A, et al. Standardisation of spirometry. Eur Respir J. 2005;26(2):319-38.

23. Pauwels RA, Buist AS, Calverley PM, Jenkins CR, Hurd SS. Global strategy for the diagnosis, management, and prevention of chronic obstructive pulmonary disease. NHLBI/WHO global initiative for chronic obstructive lung disease (GOLD) workshop summary. Am J Respir Crit Care Med. 2001;163(5):1256-76.

24. Luzak A, Heier M, Thorand B, Laxy M, Nowak D, Peters A, et al. Physical activity levels, duration pattern and adherence to $\mathrm{WHO}$ recommendations in German adults. PLoS One. 2017;12(2):e0172503.

25. Choi L, Liu Z, Matthews CE, Buchowski MS. Validation of accelerometer wear and nonwear time classification algorithm. Med Sci Sports Exerc. 2011:43(2):357-64.

26. Freedson PS, Melanson E, Sirard J. Calibration of the computer science and applications. Inc accelerometer Med Sci Sports Exerc. 1998;30(5):777-81.

27. World Health Organization. Global recommendations on physical activity for health. Geneva: World Health Organization; 2010. http://www.who.int/ dietphysicalactivity/factsheet_recommendations/en/. Accessed 13 Oct 2016

28. Macintyre N, Crapo RO, Viegi G, Johnson DC, van der Grinten CP, Brusasco $V$, et al. Standardisation of the single-breath determination of carbon monoxide uptake in the lung. Eur Respir J. 2005;26(4):720-35.

29. American Thoracic Society/European Respiratory Society. ATS/ERS Statement on respiratory muscle testing. Am J Respir Crit Care Med. 2002;166(4):518624.

30. Quanjer PH, Stanojevic S, Cole TJ, Baur X, Hall GL, Culver BH, et al. Multiethnic reference values for spirometry for the 3-95-yr age range: the global lung function 2012 equations. Eur Respir J. 2012;40(6):1324-43.

31. R Core Team. R: a language and environment for statistical computing. Vienna, Austria: R Foundation for Statistical Computing; 2017. URL https:// www.R-project.org

32. Krug S, Jordan S, Mensink GBM, Müters S, Finger JD, Lampert T. English version of "Körperliche Aktivität. Ergebnisse der Studie zur Gesundheit Erwachsener in Deutschland (DEGS1)" Bundesgesundheitsblatt. 2013;56:76571.

33. Ju C, Liu W, Chen RC. Twitch mouth pressure and disease severity in subjects with COPD. Respir Care. 2014;59(7):1062-70.

34. Abramson MJ, Kaushik S, Benke GP, Borg BM, Smith CL, Dharmage SC, et al. Symptoms and lung function decline in a middle-aged cohort of males and females in Australia. Int J Chron Obstruct Pulmon Dis. 2016;11:1097-103.

35. Tang W, Kowgier M, Loth DW, Soler Artigas M, Joubert BR, Hodge E, et al. Large-scale genome-wide association studies and meta-analyses of longitudinal change in adult lung function. PLoS One. 2014;9(7):e100776.

36. Garcia-Aymerich J, Lange P, Benet M, Schnohr P, Anto JM. Regular physical activity modifies smoking-related lung function decline and reduces risk of chronic obstructive pulmonary disease: a population-based cohort study. Am J Respir Crit Care Med. 2007;175(5):458-63.

37. Petersen AM, Pedersen BK. The anti-inflammatory effect of exercise. J Appl Physiol (1985). 2005;98(4):1154-62.

38. National Center for Chronic Disease P, Health Promotion Office on S, Health Reports of the surgeon general. In: The health consequences of Smoking-50 years of progress: a report of the surgeon general. Edn. Atlanta (GA): Centers for Disease Control and Prevention (US); 2014. 